http://ejournal.upi.edu/index.php/jaz - e-mail: jurnal_zonasi@upi.edu doi.org/10.17509/jaz.v4i2.33895

\title{
REDEFINISI ARSITEKTUR MONUMEN PERJUANGAN DI INDONESIA: Arsitektur Monumen Sebagai Refleksi Cita-Cita
}

Article History:
First draft received:
30 April 2021
Revised:
19Mei 2021
Accepted:
24 Mei 2021
Final proof received:
Print:
15 Juni 2021
Online
15 Juni 2020
Jurnal Arsitektur ZONASI
is indexed and listed in
several databases:

SINTA 4 (Arjuna)

GARUDA (Garda Rujukan Digital)

Google Scholar

Dimensions

oneSearch

BASE

Member:
Crossref
RJI
APTARI
FJA (Forum Jurna Arsitektur)
IAI
AJPKM

\section{Cipta Hadi ${ }^{1}$}

Restu Minggra ${ }^{2}$

${ }^{1}$ Universitas Indonesia, Jalan Kampus UI, Kukusan, Beji, Kukusan, Kecamatan Beji, Kota Depok, Jawa Barat 16424

${ }^{2}$ Universitas Pendidikan Indonesia, J1. Dr. Setiabudi No.207, Isola, Kec. Sukasari, Kota Bandung, Jawa Barat 40154

Email: ciptahad@gmail.com, $\underline{\text { rminggra@upi.edu }}$

Abstract: Does the architectural expression of the monument of battle can be more than commemorating the past event? How to re-introduce human scale in architecture of the monument in Indonesia? This paper is a review of a project as a design research to find the answers to those questions. The architecture of the monument of battle in Indonesia has not only a limited meaning and expression, but also failed to fulfil its function as public space. Through the design competition of Balikpapan monument of battle held by Ikatan Arsitek Indonesia (Indonesian Architect Association), an idea of monument without "monument" is explored. Literature study is conducted as a base theory to understand monument and monumental. In addition, precedent study also conducted from previous works which based on that theory. This research uses anti-monumental and dialogical as a design approach. This monument design is a proposition to add a value for monument of battle not only as a past event commemoration, but also as an embracement of the future goals of the battle itself on the one hand and re-introduce human scale to the architecture of monument on the other.

Key words: architecture, monument, human, public space

Abstrak: Apakah ekspresi arsitektur monument perjuangan bisa lebih dari sekadar peringatan peristiwa lampau? Bagaimana memperkenalkan kembali skala manusia pada arsitektur monument di Indonesia? Tulisan ini mengenai ulasan proyek sebagai riset desain untuk menemukan jawaban dari pertanyaan-pertanyaan tersebut. Arsitektur monumen perjuangan di Indonesia memiliki makna dan ekspresi yang terbatas dan gagal dalam memenuhi fungsinya sebagai ruang publik bagi manusia. Melalui kompetisi desain monumen perjuangan Balikpapan yang diadakan Ikatan Arsitek Indonesia (IAI) dilakukan eksplorasi sebuah ide desain monumen tanpa 'monumen'. Dilakukan studi literatur sebagai dasar teori memahami makna monumen dan monumental, serta studi preseden dari karya-karya arsitek yang menerapkan pendekatan desain berdasarkan dasar teori tersebut. Riset ini menggunakan dasar teori anti-monumental dan dialogical sebagai pendekatan dalam mendesain. Desain monumen ini merupakan upaya menambah nilai entitas tidak hanya sebagai peringatan peristiwa lampau, namun juga sebagai penyongsong citacita masa depan dan memperkenalkan kembali skala manusia pada arsitektur monumen.

Kata kunci: arsitektur, monumen, manusia, ruang publik 


\section{Pendahuluan}

Tulisan ini merupakan ulasan proses perancangan dan hasil desain sekaligus bentuk riset desain dari Sayembara Revitalisasi Monumen Perjuangan Rakyat (Monpera) Balikpapan. Kawasan monumen berada di pusat Kota Balikpapan tepatnya di Jl. Jendral Sudirman. Konteks kawasan monumen dikelilingi bangunan yang memiliki nilai heritage tinggi, yaitu terdapat patung Jendral Sudirman dan markas Kodam di sisi Utara dan Bank Indonesia di sisi Timur. Sedangkan di sisi Selatan, berbatasan dengan pantai dan menghadap ke laut. Di dalam kawasan tersebut terdapat monumen berupa patung tiga pejuang yang terdiri dari dua prajurit tentara Indonesia dan satu prajurit asli rakyat Balikpapan. Monumen tiga patung pejuang itu roboh setelah 33 tahun berdiri dan hanya menyisakan pedestal trapesium berbentuk tangga di bawahnya. Berdasarkan fenomena yang terjadi, diselenggarakan sayembara desain untuk merevitalisasi kawasan Monpera Balikpapan dengan tujuan menemukan desain landmark yang baru.

Desain yang diharapkan oleh pemerintah setempat dicantumkan dalam dokumen Kerangka Acuan Kerja (KAK) sayembara sebagai pondasi dasar dalam menetapkan visi perancangan. Desain monumen harus dapat mencirikan identitas kawasan, baik menggambarkan masa lalu, memori sebuah kawasan, maupun gambaran masa depan. Desain monumen juga harus mudah dikenali, dikenang, dan dikagumi. Selain itu, desain monumen diharapkan dapat berfungsi untuk membantu orang dalam mengarahkan diri pada titik orientasi tertentu pada sebuah lokasi. Desain monumen yang baru diharapkan dapat melebur dengan skala lingkungan, dapat dinikmati oleh orang yang berkendara di sekitar monumen, dan dapat terintegrasi dengan kawasan wisata di sekitar lokasi monumen. (IAI Balikpapan, 2019)

Kriteria desain ditetapkan oleh pemerintah setempat untuk memberikan koridor yang sesuai dalam perancangan desain kawasan monumen yang baru. kriteria pertama mengatur tentang pengembangan perencanaan dan perancangan monumen yang harus sesuai dengan masterplan kawasan. Selain itu, Desain revitalisasi kawasan diharapkan dapat mengakomodir kesinambungan dan keserasian dengan konsep yang sudah terbangun dan konsep lingkungan di sekitar kawasan. Pemerintah setempat menginginkan agar ekspresi desain tetap memperhatikan nilai sejarah, nilai budaya, nilai identitas, nilai kesinambungan, serta memperhatikan value monumen di masa depan. terakhir, dari segi teknis, desain harus mudah untuk dibangunan, dan memperhatikan pemilihan material dan komponen desain yang memudahkan dalam pemeliharaan. (IAI Balikpapan, 2019)

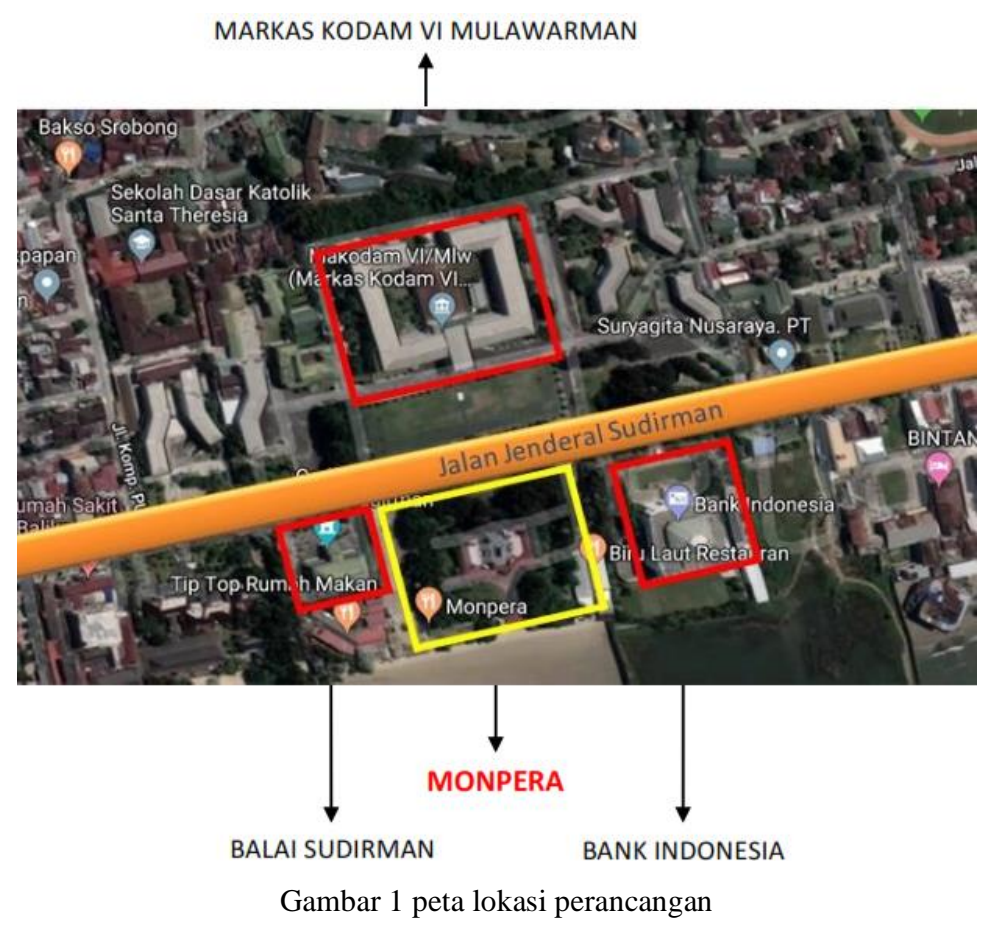

Beberapa poin dalam tujuan dan kriteria perancangan masih dapat diperdebatkan. Pada kesempatan ini, pertimbangan mengenai pengendara sebagai mayoritas penikmat kawasan monumen serta kriteria desain yang menekankan pada keselarasan dan keserasian ekspresi desain menjadi perhatian utama pengembangan gagasan desain ini. Kritik pertama menyoroti tentang permasalahan perancangan kota dimana terisolasinya bangunan maupun sebuah tempat (place), terpisah dari keseluruhan jalan, ruang kota, dan ruang terbuka lainnya. 
Fenomena ini disebut sebagai "lost space", yang munculnya disebabkan oleh perkembangan kota yang berorientasi pada kendaraan bermotor khususnya kendaraan pribadi (trancik,(1986) Pengendara sebagai prioritas penikmat kawasan monumen merupakan suatu indikasi atau potensi akan terjadinya sebuah "lost space". Oleh karena itu, orientasi dan prioritas bagi perancangan kawasan monumen ini perlu diubah menjadi ke manusia sebagai penikmat.

Selain kritik terhadap kriteria yang ditetapkan, desain-desain monumen perjuangan di Indonesia yang sudah terbangun juga memiliki isu yang patut direspon. Salah satu isu tersebut adalah bentuk ekspresi atau wujud monumen yang terbatas. Karakteristik arsitektur monumen di Indonesia secara tidak langsung seperti sudah terbentuk dan terus berulang, hanya berbeda lokasi. Metafora dari senjata bambu runcing, bentuk desain yang simetris, ekspresi struktur yang vertikal (menjulang tinggi ke atas), atau berupa patung/sculpture harfiah maupun abstrak. Ekspresi vertikal umumnya menjadi focal point bagi keseluruhan kawasan yang formal dan monumental. Template desain seperti diungkapkan sebelumnya mengakibatkan skala manusia di dalam desain terabaikan. Muncul rasa tidak nyaman dan keengganan untuk beraktivitas di kawasan sekitar monumen selain sekadar melihat megahnya monumen dan berfoto. Yang patut dipertanyakan ialah, apakah karakter-karakter tersebut merupakan karakter mutlak bagi arsitektur monumen perjuangan di Indonesia?

Berdasarkan studi Santoni dkk., tentang desain taman Monumen Perjuangan Kota Bandung, Taman Monpera kota Bandung dinilai kurang berhasil dalam menjalankan fungsi sebagai ruang publik yang menyenangkan, dilihat dari aktivitas sehari-hari yang kurang ramai, kecuali pada hari Minggu. Bentuk taman yang linear dan berkesan formal bertolak belakang dengan karakter manusia sebagai pengguna yang sangat dinamis dan informal (Santoni, Keumala, \& Fecianti, 2018). Studi tersebut juga mengindikasikan hal yang sama juga terjadi pada desain-desain monumen lainnya di Indonesia yang memiliki karakterisitik desain yang serupa, termasuk Monpera Balikpapan. Tertutupnya kawasan memiliki Monpera Balikpapan dengan pagar dan desain yang formal membuat kawasan tersebut tidak aktif sebagai ruang publik. Sesuai dengan pendapat Cudny dan Appleblad, dalam kajiannya mengenai monumen bahwa monumen memiliki pergeseran fungsi yang bukan hanya memiliki fungsi art dan symbolic, namun juga experiencing, social, religious, political, bahkan marketing (Cudny \& Appelbad, 2019). Monumen sebagai ruang publik yang aktif perlu untuk didorong pada konteks monumen perjuangan di Indonesia. Terbatasnya makna dan ekspresi arsitektur monumen di Indonesia dan absennya aspek manusia menjadi isu utama pada tulisan dan perancangan kali ini. Dua pertanyaan utama yang diajukan antara lain; Apakah ekspresi arsitektur monumen perjuangan bisa lebih dari hanya peringatan peristiwa lampau? Bagaimana memperkenalkan kembali skala manusia pada arsitektur monument di Indonesia? Selanjutnya tulisan ini akan membahas bagaimana pertanyaan tersebut dapat dijawab dan diwujudkan dalam bentuk sebuah desain kawasan monumen perjuangan.

Metode dalam pengembangan ide desain dimulai dari studi literatur dan studi preseden. Studi literatur digunakan untuk memahami kembali makna dari monumen dan monumentality dari teori lama hingga terbaru. Pertama, mengulas etimologi dari kata "monumen", lalu membahas monumentality oleh Louis Kahn, lalu S. Giedion, dan terbaru teori mengenai anti-monumental dan dialogic (Quentin, Franck, \& Fazakerley, 2018). Selanjutnya ditarik kesimpulan yang menjadi basis gagasan dan kriteria perancangan kedepannya. Kedua, memahami karya-karya yang menggunakan teori tersebut. Abstraksi nilai-nilai yang diterapkan oleh karya tersebut dan menerapkannya pada konteks desain kawasan monumen perjuangan Balikpapan.

\section{Kajian Literatur}

\subsection{Monumen; etimologi dan makna}

Monumen berasal dari bahasa Latin, monumentum yang berarti "apapun yang memanggil kembali ingatan orang" (Partridge, 2006). Namun, kata tersebut merupakan turunan dari kata monēre yang berarti "to remind or warn" atau untuk "mengingatkan atau memperingatkan/mengumumkan" (Partridge, 2006). Jika makna "remind" berkaitan dengan masa lampau, maka "warn" berkaitan dengan masa yang akan datang. Jadi, monumen tidak hanya terbatas pada makna kaitan dengan masa lampau, tapi juga masa depan. Lalu, kata "monumental" berarti memiliki makna sesuatu yang memiliki sifat "monumen". Monumen adalah objek, sedangkan monumental ada sifatnya. Sebuah monumen harus memiliki sifat monumental, namun monumental dapat melekat pada objek apapun.

Monumentalitas dapat didefinisikan sebagai sebuah kualitas, yaitu kualitas rohaniah yang melekat pada sebuah struktur yang membawa perasaan kekekalannya (Kahn, 1944). Menurut Kahn, monumentalitas tersebut tidak dapat ditambahkan maupun diubah. Sebuah monumentalitas yang ditimbulkan dari bangunan masa lampau seperti Parthenon pada masa peradaban Yunani tidak bisa diulang kembali di masa sekarang. Sebab, 
monumentalitas sangat melekat pada hasrat, kecintaan, kebencian, dan nilai-nilai masyarakatnya. Namun berarti monumentalitas dapat tumbuh dari ruh masyarakat pada masanya. Sebagaimana perhatian Kahn pada masa itu, arsitektur modern tentu bisa mencapai sebuah kemonumentalannya sendiri, dengan kemajuan teknologi dan ragam materialnya.

Seorang sejarawan arsitektur, Sigfried Giedion, juga mengemukakan pendapatnya mengenai "monumentality" melalui tulisannya "Nine Points of Monumentality" (Giedion, 1958). Menurutnya, monumen adalah landmark manusia yang diterjemahkan sebagai symbol dari idelisme, tujuan, dan aksi mereka. Monumen merupakan ekspresi kebutuhan kultural tertinggi manusia pada eranya. Sehingga, monumen harus bisa hidup melampaui masanya dan menjadi sebuah warisan bagi generasi mendatang. Pernyataan tersebut menunjukkan bahwa monumen sarat akan makna. Kahn maupun Giedion sepakat bahwa monumen erat berkaitan dengan makna yang dikandungnya dari semangat zamannya (dan manusianya).

\subsection{Pendekatan Counter-monument dan penerapannya}

Tidak berhenti disitu, diskursus mengenai monumen masih berlanjut hingga sekarang. Counter-monument diartikan sebagai kontradiksi dari desain "monumen" beserta karakter yang melekat padanya. Secara garis besar, unsur-unsur yang dapat menunjukkan perbedaan tersebut antara lain pada unsur subjek, bentuk, lokasi, pengalaman dan pemaknaan. Subjek pada counter monument akan lebih berfokus pada pembentukan karakter suasana kejadian daripada figur tokoh / pelaku. Ekspresi bentuk akan banyak berdialog dengan kehampaan, ketidakhadiran, nuansa gelap, dan terbangun dalam skala-skala manusia (horizontal). Pemilihan lokasi monumen diluar garis axis dan menghindari keagungan atau keutamaan yang simetris. pengalaman monumen pada umumnya cenderung membutuhkan jarak terhadap penikmatnya bahkan membutuhkan perhatian khusus untuk menikmatinya, sedangkan anti-monumental cenderung lebih dekat dan intim. Terakhir, makna antimonumental memiliki keambiguan t,ergantung pada interpretasi dari penikmatnya. (Quentin, Franck, \& Fazakerley, 2018).

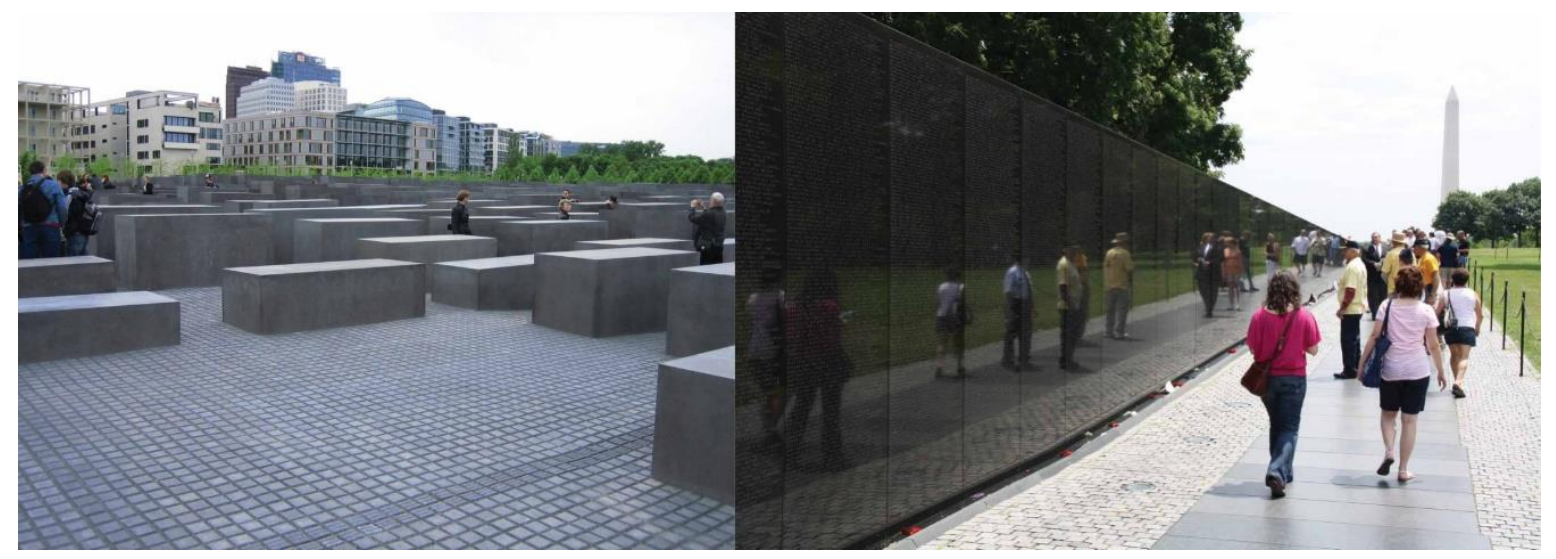

Gambar 2 karya Peter Eisenman (kiri) dan Maya Lin (kanan)

Pendekatan anti monumental ditunjukkan oleh karya Maya Lin yaitu dalam desain Vietnem Veterans Memorial. Monumen ini dbangun untuk menghormati tentara Amerika Serikat yang gugur saat perang vietnam pada tahun 1955. Dilihat dari morfologinya, Vietnam Veterans Memorial berbentuk sodetan pada gundukan tanah yang dindingnya dilapisi oleh batu hitam bertuliskan nama-nama korban peperangan. Secara bentuk, situs monumen ini tidak terlihat dari kejauhan kecuali datang langsung untuk mengunjungi atau melewatinya. Sifat ke-horisontal-an dari anti-monumental sangat kental ditunjukkan dengan monumen yang membangun suasana menggugah dengan cara memrefleksikan bayangan pengunjung pada marmer hitam yang bertuliskan nama pejuang yang gugur, menyimbolkan kehadiran dan keterikatan antara yang mati (past) dan yang hidup (present and hope). Sifat ke-horisontal-an tersebut juga ditunjukkan oleh karya Peter Eisenman yang berupa balok beton kosong (tanpa tulisan) yang tersebar diseluruh area dengan beragam ketinggian.

Sebagai kesimpulan, studi literatur yang telah dilakukan menunjukkan bahwa makna monumen lebih dari sekadar peringatan masa lampau. Selain itu, pada dasarnya monumen tidak memiliki karakteristik yang bersifat wujud maupun bentuk, melainkan makna yang terkandung di dalamnya. Hal tersebut diperkuat oleh aksi dari gerakan counter-monuments yang termanifestasi pada karya Maya Lin dan Peter Eisenman. Karya tersebut menunjukkan ekspresi monumen dapat berwujud sangat beragam tergantung makna yang ingin dikandung dan pendekatan yang digunakan. Oleh karena itu, arsitektur monumen masih sangat terbuka luas untuk dieksplorasi. 


\section{Hasil dan Pembahasan}

Anti-monument dijadikan sebagai pendekatan dalam proses pengembangan dan perancangan desain Monpera Balikpapan, dalam perspektif agar gagasan ini tidak hanya semata-mata terlihat beda atau unik, namun memiliki pesan bahwa monumen memiliki makna yang lebih luas dari sekedar struktur figuratif.

Monumen bukan hanya sekadar peringatan peristiwa lampau. Monumen juga memiliki makna "to warn" atau memperingati sesuatu yang akan datang di masa depan. Cita-cita perjuangan rakyat dijadikan sebagai visi dasar dalam gagasan ini. selain peristiwa itu sendiri, dibalik sebuah perjuangan, ada tujuan atau cita-cita yang ingin diraih. gagasan ini menggeser fokus makna maupun fungsi sebuah arsitektur monumen perjuangan di Indonesia dari peringatan masa lampau menjadi masa depan. Dalam upaya untuk mengaplikasikan pendekatan "counter monuments", terdapat tiga strategi desain yang diterapkan.

Strategi pertama ialah dengan memutar fokus yang sebelumnya menuju satu titik focal point yakni sturktur monumen figuratif tunggal, menjadi tersebar ke seluruh penjuru orientasi monumen, dimana targetnya adalah kota Balikpapan itu sendiri. Dalam visi perancangan yang sudah disebutkan sebelumnya, "monumen" merupakan representasi atau symbol dari sebuah peristiwa perjuangan, sedangkan kota Balikpapan merupakan cita-cita dari perjuangan itu sendiri. Narasi yang dibangun adalah kawasan yang sebelumnya memiliki "monumen" dengan orientasi tunggal dan memusat, menjadi sebuah kawasan yang berorientasi kepada konteks yang lebih luas, setara dan lebih fleksibel. Narasi berlanjut dengan desain yang diajukan akan lebih berorientasi kepada pengalaman manusia sebagai pengguna dalam mengalami ruang di dalam kawasannya. Perancangan kawasan monumen ini bergeser dari merancang sebuah "monumen" menjadi sebuah ruang terbuka publik. Strategi ini merupakan ide yang sangat fundamental dan berpengaruh pada strategi perancangan kedepannya.

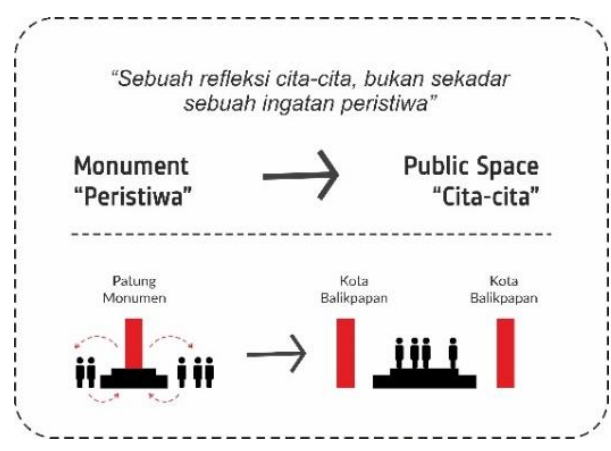

Gambar 3 diagram konsep re-orientasi

Kedua, untuk melakukan strategi pertama, hal yang perlu dilakukan ialah menaikkan elevasi plasa utama untuk mendapatkan view kota secara maksimal. Kenaikan elevasi dibuat bertahap mulai dari sisi jalan, lalu dinaikkan satu level bangunan (sekaligus memanfaatkan podium eksisting monumen sebagai acuan tinggi level) hingga turun lagi di sisi yang menghadap pantai.

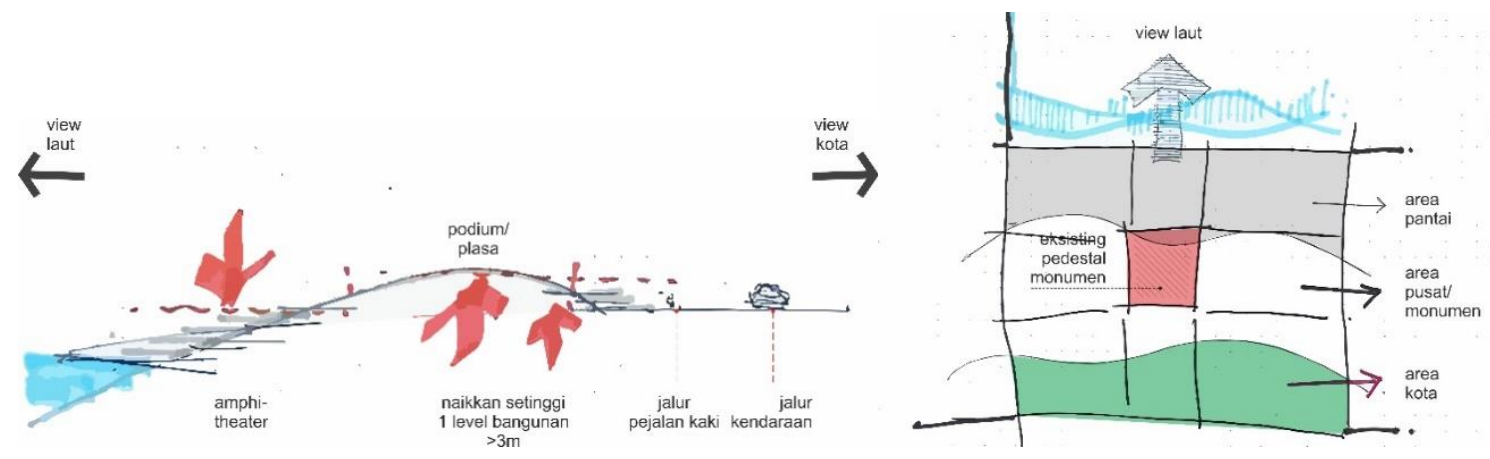

Gambar 4 diagram konsep elevasi plasa/podium (kiri) dan konsep zona (kanan)

Ketiga, transformasi tiga patung menjadi tiga zona utama di kawasan. Tiga patung yang sebelumnya sebagai "monumen" inilah yang disingkirkan dan menjadi zona-zona yang lebih bersifat menyebar dan membentuk kesetaraan ruang. Tiga zona tersebut antara lain, 1) zona taman bambu, representasi dari prajurit Indonesia yang pertama. Pohon bambu dipilih karena pada umumnya monumen atau tugu perjuangan di Indonesia merupakan metafora dari senjata prajurit kala itu, yaitu bambu runcing. Namun, pada gagasan ini dipilih pohon 
bambu alami agar secara fungsi alami tanaman masih dapat berguna bagi kawasan tanpa menghilangkan nilai simbolis dari senjata bambu runcing itu sendiri, yaitu terbuat dari bambu; 2) zona museum perjuangan, representasi dari prajurit Indonesia kedua. Museum perjuangan ini terletak di bawah plasa/podium utama yang juga sekaligus memanfaatkan ruang diorama yang ada dibawah pedestal eksisting. Zona museum perjuangan ini nanti selain memiliki ruang diorama, juga memiliki ruang serba guna yang dapat digunakan untuk keperluan kegiatan kebudayaan atau pendidikan; 3) zona plasa/podium utama dan amphiteater, representasi dari prajurit rakyat Balikpapan. Sebagai representasi prajurit rakyat Balikpapan, plasa/podium ini diberikan pola material dengan corak asli Balikpapan agar menunjukkan identitas visual budayanya.
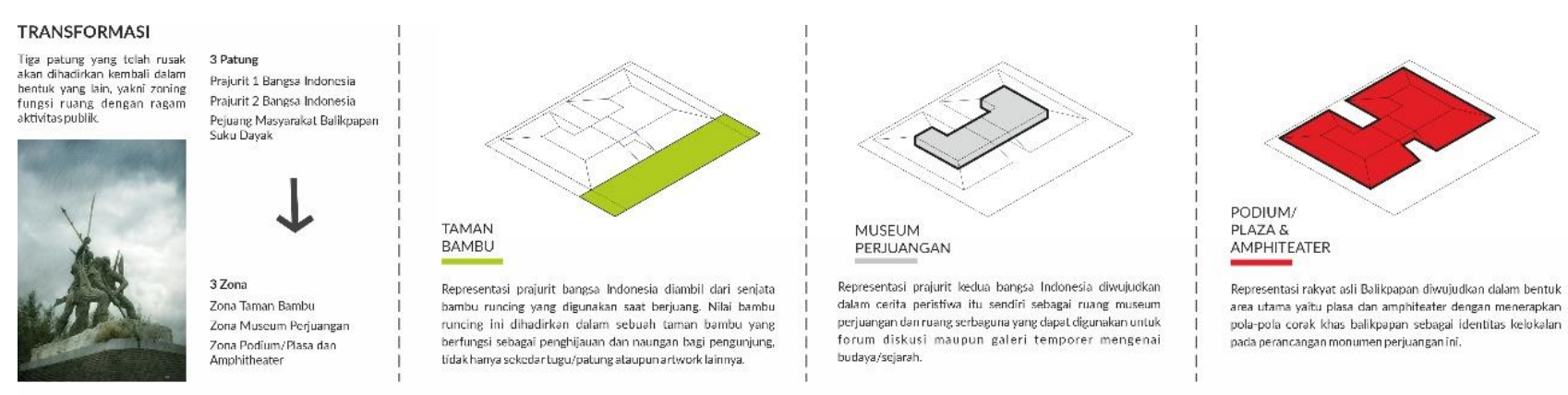

Gambar 5 konsep transformasi patung menjadi zona

Secara keseluruhan, desain kawasan monumen perjuangan rakyat Balikpapan ini merupakan desain ruang terbuka publik yang terdiri dari area taman bambu, plasa/podium utama, dan amphiteater yang menghadap pantai, serta museum perjuangan yang terletak di bawah podium utama. Taman bambu pada area depan berfungsi sebagai penerima dan pembingkai pemandangan ke arah podium utama melalui susunan pohon bambu yang sejajar. Bagi para pengendara, hal ini juga sekaligus memberikan kesan misterius agar bersifat attraktif dan meningkatkan keinginan untuk mengunjungi secara langsung kawasan monumen. Kawasan monumen dapat diakses melalui semua sisi, serta podium utama juga dikelilingi oleh tangga. Selain itu, untuk meningkatkan inklusifitas pada kawasan, dibagian utara diterapkan kombinasi tangga dan ramp agar penyandang disabilitas (pengguna kursi roda) juga dapat mengakses kawasan. Terakhir, pada permukaan podium utama dan amphiteater menggunakan material yang disusun berbentuk corak asli Balikpapan.

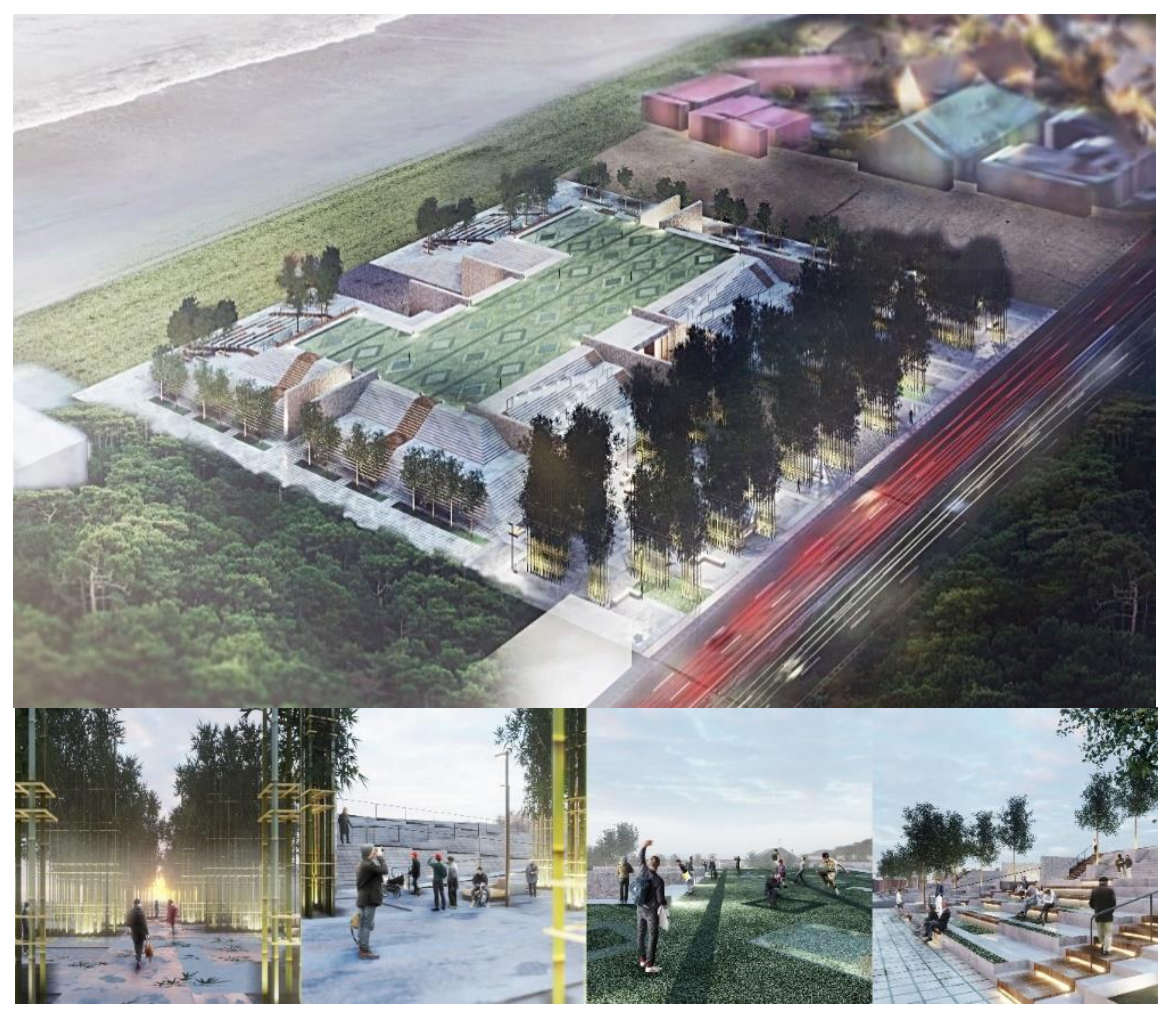

Gambar 6 view perspektif udata (atas) dan suasana kawasan (bawah) 


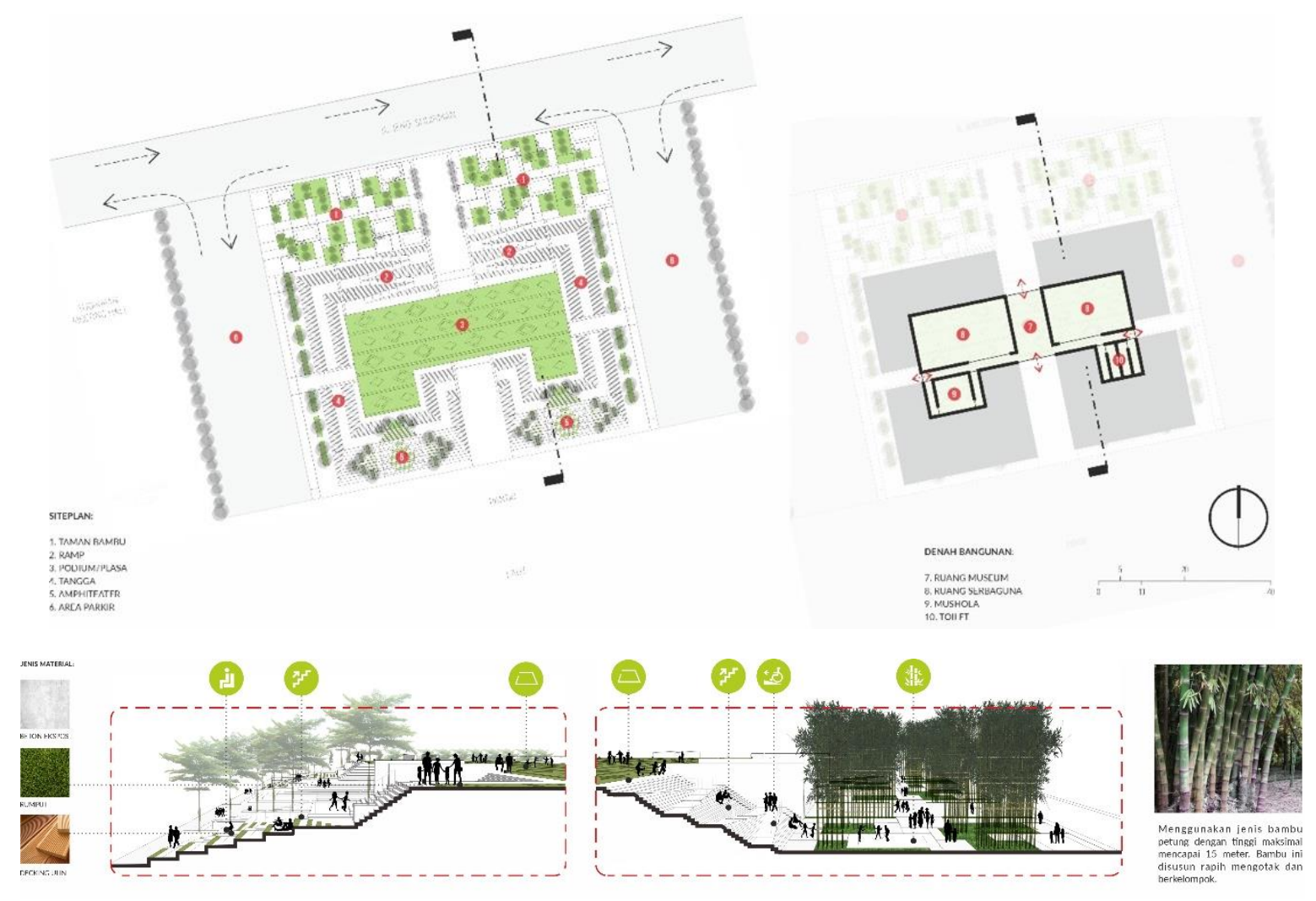

Gambar 7 rencana tapak (atas) dan potongan kawasan (bawah)

\section{Kesimpulan}

Gagasan ini merupakan bentuk redefinisi arsitektur monumen perjuangan khususnya di Indonesia. Sebagai rangkuman, gugatan pada gagasan ini ialah makna terbatas monumen hanya sebagai peringatan peristiwa dan "monumen" (berupa patung/sculpture/dll) sebagai representasinya. Tinjauan literatur dan preseden yang telah dilakukan berpendapat lain. Arsitektur monumen masih dapat dieksplor lebih jauh. Makna monumen bukan hanya mengenai masa lampau akan tetapi juga masa depan. Dengan mengeksplor makna monumen yang lebih luas, ekspresi dan perancangan kawasan monumen perjuangan memiliki bentuk, citra, serta fungsi yang sangat berbeda.

Khususnya pada perancangan kawasan monumen perjuangan Balikpapan ini, dengan melakukan transformasi patung menjadi zona-zona kawasan monumen, lalu dirancang sebagai ruang terbuka publik yang aktif dan mendorong beragam aktivitas publik, sebuah ekspresi arsitektur monumen perjuangan menjadi eksploratif dan beragam. Hal ini perlu dilakukan agar aspek manusia sebagai pengguna dan penikmat kembali diperkenalkan dan menjadi yang utama dalam sebuah arsitektur monumen perjuangan rakyat.

\section{Referensi}

Brolin, B. C. (1982). Architecture in Context. New York: Van Nostrand Reinhold.

Cudny, W., \& Appelbad, H. (2019). Monuments and their functions in urban public. Norsk Geografisk Tidsskrift - Norwegian Journal of Geography, 273-289.

Giedion, S. (1958). Architecture You and Me: The diary of a development. Cambridge: Harvard University Press.

IAI Balikpapan, B. (2019). Kerangka Acuan Kerja Sayembara Revitalisasi Kawasan Monumen Perjuangan Rakyat Balikpapan. IAI Balikpapan.

Jacobs, J. (1961). The Death and Life of Great American Cities. New York: Random House, Inc.

Kahn, L. (1944). Monumentality. In R. Twombly, Louis Kahn Essential Texts (pp. 21-31). New York: W.W. Norton \& Company. 
Partridge, E. (2006). Origins; A Short Etymological Dictionary of Modern English 5th Edition. London: Taylor $\&$ Francis Group.

Quentin, S., Franck, K. A., \& Fazakerley, R. (2018). Counter-monuments: the anti-monumental and the dialogic. The Journal of Architecture, 23:5, 718-739.

Santoni, Keumala, I., \& Fecianti. (2018). ANALISIS KRITERIA RUANG PUBLIK PENDUKUNG PERUBAHAN RUANG PASIF MENJADI AKTIF PADA TAMAN MONUMEN BANDUNG. Architecture Innovation Vol 2 No 2, 11-21.

Trancik, R. (1986). Finfing Lost Space. New York: Van Nostrand Reinhold Company Inc.

Webber, P. (2001). The Public Space and the Monuments of the City. Architectural Theory Review, 6:2, 95106. 